\title{
EFFECT OF TEACHERS' EMOTIONAL INTELLIGENCE ON STUDENT' INVOLVEMENT AND TASK ORIENTATION IN CLASSROOM LEARNING ENVIRONMENT AT SECONDARY SCHOOL LEVEL
}

\author{
Nida Iram \\ Ph.D. Scholar, \\ Institute of Education and Research, University of Punjab, \\ Punjab, Pakistan \\ Email: nidawaqas225@gmail.com
}

\author{
Abida Nasreen \\ Associate Professor, \\ Institute of Education and Research, University of Punjab, \\ Punjab, Pakistan \\ Email: nasreen.ier@pu.edu.pk
}

\begin{abstract}
Emotional intelligence plays an important role in teaching and learning process specially when it is about students' involvement and task orientation in classroom. The main objective of this research work is to discover the effect of teachers' emotional intelligence on secondary school level students' involvement and task orientation in classroom learning environment. Quantitative research was design by using a causalcomparative method. The study objectives were to explore the effect of teachers' emotional intelligence of secondary school on students' involvement and task orientation in classroom learning environment. The population of study was based on female teachers and students at public secondary schools of Lahore. The data collection was done by using a simple random sampling technique. Two questionnaires were used to find out the cause and effect between teachers' emotional intelligence and students' involvement and task orientation in classroom learning environment. The questionnaire was adapted from "what is happening in this Class" and the second was "Social Emotional Teacher Rating Scale (SETRC)". The data interpretation is done by utilization of various descriptive statistical techniques such as correlation, simple linear regression, standard deviation, and Inferential statistics one-way ANOVA etc. The analysis of research work presents a strong effect of teachers' emotional intelligence on students' involvement and task orientation in classroom learning environment. The results showed that teachers' emotional intelligence must
\end{abstract}


be kept in concern all the time in school. Consequently, it will be beneficial for the educational administrators to promote healthy \& positive classroom learning environment/climate and enhance productivity of staff in learning and teaching at the secondary school level.

\section{KEYWORDS}

Teachers' emotionally intelligence, Student cohesiveness, Classroom learning environment, Secondary school

\section{INTRODUCTION}

One of the main reasons for man's superiority over other creatures is that man, in comparison to other creatures, not only has the ability to express his emotions and control them, but also understands and interprets the feelings and emotions of others. As a result, they respond appropriately. As a human being, this act is not only a proof of human dignity but also a measure of the progress of societies. One need to be wise while expressing the emotions and if you are a teacher, you have a big responsibility to manage it all. Akin-Little et al. (2007) explained that classroom learning environment is very important aspect in effective teaching. They have also presented that effective teaching and classroom environment have strong relationship to each other. The effective classroom environment is very beneficial to increase the likelihood of student engagement and learning in the classroom. The effective classroom environment and good school climate has positive impact on students' engagement and assist to decrease disruptive behaviour in school. It also enables teachers to efficiently use the instructional time (Johansen et al., 2011).

According to Pugazhenthi and Srinivasan (2018), the teachers should be emotionally resilient and intelligent to acknowledge the behaviours, events, and activities in classroom. This is one important aspect to be successfully create effective and interesting classroom environment. The emotional intelligence encourages towards creative thinking and involving emotions for better problem solving. It is also important to acknowledge that emotional intelligence is not same as general intelligence, though these probably overlap to some extent. An emotionally intelligent person has valuable skills in these four areas: emotions recognition, use of emotions, acknowledgement of emotions and emotions regulation. These areas are very vital to understand for teachers and educators (Desti \& Shanthi, 2015).

The effective classroom learning environment can have constructive impact on the chance of students' positive behaviour and also on their engagement and learning in classroom. It is possible to interpret classroom management in numerous ways. However, various procedures and techniques are available for teacher's help to attain better classroom learning environment and maintain healthy school climate (Akin- 
Little et al., 2007). Jeloudar et al. (2011) presented that emotional intelligence has significant importance in students' performance improvement in classroom. The emotional intelligence has constructive impact on students' confidence and their selfcontrol. It has also positive influence on student's communication skills and social/emotional behaviour.

According to Swift (2018), there is great influence of emotional intelligence in teaching profession within the classroom. He mentions the importance to examine whether the level of teacher's emotional intelligence has any significant relation with the students 'involvement in classroom or not. There is a level of satisfaction of teachers which can provide insight for the development of necessary progress in modern schools.

\section{Statement of the Problem}

The challenges in the school are not only encountered by teachers but also students have to face various issues and challenges in school, such as social affairs, stress to accomplish excellent academic performance, and different forms of bullying (Sadker \& Sadker, 2005; Davis, 2005; CDC, 2012). In schools, administrators and teachers are under pressure to take corrective actions for betterment. The cultural background and experiences of children coming to school are not necessarily same and often they are having a variety of backgrounds and experiences. Because of this, it is very likely that they might confront academic struggle as well as may face personal and socioemotional problems, that can influence negatively their learning and academic performance. According to Jeloudar et al. (2011), effective classroom learning environment is very useful to enhance the student engagement and also decrease the disruptive behaviour of students in classroom. It enables teachers to efficiently use the instructional time in classroom. Emotional intelligence effectively compliments the sense of creativity and originality. It also assists in paradigm shift towards innovative approach, calmness, reducing stress and creating/maintaining healthy relationships.

In this situation, teachers need to find the connection and effect between the learning environment and emotional intelligence in the classroom. In order to assess the impact of teachers' emotional intelligence on work familiarity and student involvement in the classroom learning environment. It is also important to identify and acknowledge the perception and opinion of both, teachers and students, related to this subject. In this study, the research work is carried out mainly in secondary schools of Lahore, Punjab province that aims towards filling the gaps and identify the modern emerging constructs in the field of education. The primary focus of research work is on secondary school level, to enlighten and explore the effect on classroom learning environment by teacher's emotional intelligence, keeping in view students' involvement and task orientation. 


\section{LITERATURE REVIEW}

The importance of teachers' emotional intelligence for healthy and positive classroom learning environment is presented and supported in numerous research studies and literature. The healthy classroom learning environment is very important to achieve success. Emotional intelligence of teachers is one vital aspect that has significant impact on classroom learning environment. It is important to understand the link of teachers' emotional intelligence and its influence on classroom learning environment.

The emotionally intelligent teacher has capability and resourceful skills to devise a classroom learning environment that subsequently enhance the students' academic and emotional performance. In addition, the teachers' emotional intelligence has positive impact on classroom learning and students' performances (Noe, 2012).

\section{Emotional Intelligence}

The recent research supports the idea that emotional intelligence has appositive influence on schools, working places and people's lives (Bar-On et al., 2007; Freedman, 2007; Goleman, 2011). The emotional intelligence is considered "noncognitive abilities" that enables relationship understanding and competences for development of relationships. It also involves the understanding of others' feelings and utilizing them for better decisions making. Generally, it is self-regulating of own feelings adequately and motivating positively in all situations, specifically in frustrating situations. According to Desti and Shanthi (2015), the emotional intelligence is the capability to recognise, evaluate and regulate the emotions. They have also mentioned that learning and strengthening the emotional intelligence is possible through proper efforts and plan. On the other hand, it is also suggested other ways around by various researchers that it is an inborn characteristic. There are many tools developed to measure the emotional intelligence but each of them has their own approach and content.

There are various definitions available for the emotional intelligence, but most comprehensive definition is:

"The capacity for recognizing a person's own feelings and those of others, for motivating themselves and for managing emotions well in themselves and other relationships (Goleman, 1995)."

Madhar (2010) had utilised the ability model of emotional intelligence of Salovey and Mayer to explore the impact of teachers' emotional intelligence and effective classroom learning environment. Ability measures evaluate the emotional intelligence by taking into account if the inherent mental competency for emotional intelligence is possessed by individual. On the other hand, the trait measures evaluate emotional intelligence by considering if it is perceived by the persons that they have emotional 
intelligence and they also demonstrate it (Mayer et al., 2004). The emotional intelligence is comprised of five components; self-awareness, social awareness, selfmanagement, relationship skills and decision-making skill and each of them has significant influence on students' academic performance.

\section{Self-awareness}

To achieve success in life, it is important to have self-awareness skills. The selfawareness comprised of realistic self-assessment, emotional understanding, and selfconfidence. The persons having the capability of self-awareness are aware of their feelings and reason behind it. They are capable to understand the connection between their thinking, action, and feelings. They can acknowledge the effect of their feelings on their performance and have guiding awareness of their goals and values (Serrat, 2017; Palmcrantz, 2018).

\section{Self-management}

The individuals who possess the competency of self-management are capable to fulfil their commitments. They give importance to their goals and take ownership to accomplish those goals. They are competent to perform organized and progressive working. One important competency of self-management is adaptability. The person having adaptability can manage demanding situations effortlessly. He can regulate the priorities as per situation's demand and requirement as well as handle rapid changes effectively. He has the flexibility and adaptability to fit their responses in fluid circumstances (Serrat, 2017; Palmcrantz, 2018).

\section{Social awareness}

The social awareness includes empathy, service orientation and developing others. The individuals with competency of social awareness are good listeners and carefully focused on emotional cues. They acknowledge other's perspective and show sensitivity to their feelings. They understand needs of other people and exhibit empathy towards them. It is important for them to assist in development of surrounding people. The consider and respect the backgrounds, diverse views, and cultural beliefs. The discourage the biasness and intolerance and take stand against discrimination (Serrat, 2017; Palmcrantz, 2018).

\section{Relationship skills}

Relationship-skills is also very important construct of emotional intelligence which consists of communication \& collaboration, conflict management, and team building capabilities. The individuals having competency of relationship-skills are good at communication and collaboration with others. They acknowledge the emotional cues to formulate their response and effectively deliver it to others. They pay attention on other's perspective and friendly cooperative atmosphere to achieve mutual 
understanding. They promote opportunities for collaboration and build healthy relationships, while maintaining a balance between relationship management and task focus. They can handle tense situations with efficient dialogues and move towards winwin situations (Serrat, 2017; Palmcrantz, 2018).

\section{Decision making}

Another important construct of emotional intelligence is decision making which comprises of identification of problem, decision criteria establishment, produce and evaluate alternative solutions, and implement decision. It is the key element in emotional intelligence. The individuals having this competency are capable to identify the requirements and subsequent solution to problems. They are eager to take the responsibility of decision making and not afraid of it (Palmcrantz, 2018). They think out of box and just does not rely only on one solution. Rather they consider various available solutions and also generate alternative solutions to problems. They have capability to identify and implement the best solution, from the available choices. The most important they took the responsibility of their decisions, instead of blaming to others or finding excuses for obstacles or setbacks (Serrat, 2017).

\section{Classroom Learning Environment}

A classroom learning environment/climate is of great importance in effective teaching, and it has great influence on social competencies development in children(Howes et al., 1992). The numerous research studies support that health/positive classroom learning environment and emotionally sensitive teachers have significant impact on students' academic performances. It also has effect on social competencies of students and create positive influence on student's discipline issues and distress behaviour (Howes, 2000; Pianta et al., 2002).

Wilson et al., (2007) has presented the relationship of classroom learning environment and social competence of students. In their research study, they have utilised the sample data of NICHD Study of Early Child Care and Youth Development, and evaluate 820 classrooms and 946 students. They have examined the relationship among classroom type and social competences of students, and what is the possible effect of classroom environment/climate on children. They have suggested four distinct type of classroom environment/climate and mentioned that the classroom with good quality of emotional support and evaluative feedback have positive impact on students' social competencies as compared to students in other classrooms.

The classroom learning environment/climate has various subfactors but two most significant subfactors are students' involvement in classroom and task orientation in classroom. 


\section{Student Involvement in Classroom}

Marshall (2004) has presented that students' involvement in classroom is very important aspect of successful learning. He explained that the comfortable classroom environment has great positive impact on students and subsequently they enjoy classroom environment. It is the responsibility of teacher to develop interest of students and involve them in classroom practice and planning. The teachers should engage every student in classroom by asking questions about their life, interests, issues, studies and advise them to solve these issues as well as efficiently guide them how to progress constructively.

Klem and Connell (2004) also explained that classroom environment has significant influence on positive relationship management between teacher, students, and other personals. The participation of students in learning process and maintaining discipline have great importance as it not only enhances their performance but also enables them to assist other fellow students in learning. It is necessary to have comprehensive involvement of students in classroom to achieve good and positive result. It also enables teacher to create things simple and easy to implement. The teacher should encourage the students to share their opinion freely, show empathy toward them and involve them in classroom to take interest in their studies.

\section{Task Orientation in Classroom}

Akin-Little et al. (2007) has mentioned that teacher should motivate students by setting goals for them and assisting them to achieve those goals. They should devise various activities for students and encourage them to take part in these activities, it will help students to challenge themselves and explore their potential. It is also very useful to enhance team building competencies in students. It is the responsibility of teacher to create a positive classroom learning environment for students. By creating positive and healthy classroom learning environment, teachers are capable to enhance the productivity of learning process for students and help them to achieve set objectives. The teacher must provide clear and effective instructions to attain better classroom discipline and management of students. It is duty of teacher to involve students in different tasks and treat them equally without biasness. The positive classroom learning environment helps teachers to be more innovative and creative in classroom management and in turn reduce behaviour problems automatically (Salfi, 2014).

Jeloudar et al. (2011) also discussed the importance of positive classroom environment and its effectiveness for students' learning, their academic goal setting and process to achieve these goals. The favourable and positive classroom environment promotes critical thinking and innovation among students. The positive classroom learning environment helps students to perform assigned tasks comfortably and happily. It also has significant impact on students' performance and results of learning process. It is 
natural that parents have high expectation of achievements for their children and look forward to best quality instruction to be provided for them.

\section{Emotional intelligence and classroom learning environment}

The classroom learning environment is very important aspect of teaching, and it has significant impact on student learning. The emotional intelligent teachers devise the learning environment for student so that environment is felt as supportive and positive by students, and it will have great constructive impact of students learning process, innovation, and critical thinking capabilities (Jennings \& Greenberg, 2009).

Bracey (2009) also discussed about the emphasize and focus of educational research. According to him, it is important to consider and examine various possibilities and scenarios of interaction between students and teachers, and how teachers can utilise these interactions for the betterment of students' performance and personality building. The educationists understand the significance of components that are necessary to create a positive learning environment. The emotions have a significant role in creating an environment in school or class that enhance and favour towards an effective and harmonious environment for learning.

Consider the emotions of the students and teachers, have their own significant importance in creation of classroom learning environment. It is evident that good emotions are responsible for construction of good atmosphere and negative emotions have destructive impact on learning environment. Although, a high growth of student's success and achievements is related to various factors and aspects, but teacher's emotional intelligence has great and very significant impact on students' performances (Wilson et al., 2007). Osterman (2010) has presented in his research work that classroom has multiple dimensions, and a good teacher must be capable to cope with any situation. It is responsibility of teacher to create a democratic environment in classroom so that anyone will not be afraid or shy to share opinion freely. Every child should feel that they have equal right to speak and share with teacher. Also, it is very vital for teacher to pay attention and listen to their students carefully as well as understand their perspective, and work with them in a friendly manner.

According to Pugazhenthi and Srinivasan (2018), the foundation for students' motivation for learning is healthy relationship management between teachers and students. It is one of main aspects to create a healthy and positive atmosphere between teachers and students. It is very important that atmosphere for students is free of hesitation, and they should feel confident to share their perspective. In this way, both teachers are student will contribute toward the school success. Therefore, the integration of emotions and cognitions is very important to create and maintain a better, effective and efficient learning environment. Austin et al. (2005) also explained that 
students who are capable to control their impulse, are more likely to achieve high academic performances and excellent social skills. The interpersonal skills of students have significant impact on academic achievement, for example it is very important for students to have good tolerance and capability of following teacher's instruction to achieve best results. This is one main reason that students possessing strong interpersonal skills achieve good academic performance.

The teacher with high emotional intelligence is more suitable and helpful for students as it is easy for students to deal with emotionally intelligent teachers as they are open, capable to accept change, listen to understand the students' perspective and adapt to new environments (Côté \& Miners, 2006). The students become frustrated and disappointed when they are not able to achieve desire results or have to face failure. It will have negative impact on students but important is that they should be capable to regulate their negative emotions toward the positivity. This is where the role of teacher is very important, as they should guide the students, counsel then and assist them to pass through rough phase. They should help them in difficult times and assist towards positivity through emotional intelligence (Austin et al., 2005).

Salfi (2014) has mentioned that students are key factor of classroom environment. The students' interest and accomplishments in studies is possible to enhance in various ways. The role of teachers is very important to create positive classroom environment and emotionally intelligent teachers has much better capabilities to influence it. It is important to consider that a healthy and positive classroom environment is not only beneficial for students, but it also assists teacher to achieve objectives effectively. Galler (2015) has also mentioned similar conclusion in his research work that teachers' emotional intelligence (on part of effective teacher) has significant contribution to create healthy and positive classroom learning environments. The teachers having good emotional intelligence skills carefully listen students' point of view and understand their feeling which enables them to create and maintain healthy relationships with their students.

\section{RESEARCH OBJECTIVES}

1. To determine the effect of teachers' emotional intelligence on students' involvement in classroom learning environment at secondary school level.

2. To determine the effect of teachers' emotional intelligence on students' taskorientation in classroom learning environment at secondary school level.

\section{RESEARCH HYPOTHESIS}

1. There is no significant effect of teachers' self-awareness on students' involvement in classroom.

2. There is no significant effect of teachers' self-management on students' involvement in classroom. 
3. There is no significant effect of teachers' social awareness on students' involvement in classroom.

4. There is no significant effect of teachers' relationship skills on students' involvement in classroom.

5. There is no significant effect of teachers' self-awareness on students' taskorientation in classroom.

6. There is no significant effect of teachers' self-management on students' taskorientation in classroom.

7. There is no significant effect of teachers' social-awareness on students' taskorientation in classroom.

8. There is no significant effect of teachers' relationship skills on students' taskorientation in classroom.

\section{RESEARCH METHODOLOGY}

This research study is quantitative in nature, and it has used a causal comparative design. In this type of research, the focus is to determine the cause and effect of already existing difference among or between the groups (Creswell, 2013). The research study population is consisted of students and female teachers of Government secondary schools of Lahore, Punjab. From the population, a sample of 30 schools was considered that includes 15 schools from Lahore Cant and 15 schools from Lahore city. Due to COVID-19 pandemic situation its rapid spread, the sample size was delimited to Lahore, Punjab.

In this research study, two adapted questionnaires were used. The first adapted questionnaire was "Social Emotional Teacher Rating Scale" (SETRC) which was developed by Tom (2012). The five emotional competencies were considered in this research study i.e., self-awareness, self-management, social awareness, relationship skills and decision-making skills. The second adapted questionnaire was "What Is Happening in this Class" (WIHIC), developed by Khine (2001). It was used to identify and acknowledge students' perspective about classroom learning environment. The indicators of instrument were consisted of student cohesiveness, teacher support, involvement, task orientation, co-operation, and equity. In this research study, the relation of teachers' emotional intelligence is examined with two indicators i.e., students' involvement and task orientation in classroom learning environment.

The opinion of three experts had been taken to ensure the validity of the instrument about students' involvement and task orientation. Then its reliability had been ensured by pilot testing on an adequate sample of $10 \%$ from female secondary school teachers and students. All questionnaires' items were discussed with respondents. The Cronbach Alpha had been calculated to determine the reliability of students' and teachers' questionnaire. 
The data collection from teachers and students at secondary schools of Lahore, Punjab had been performed by using research instruments SETRC and WIHIC. The official permission had been taken from administrators and management of school for data collection and then questionnaires were distributed among the randomly selected teachers and students in selected secondary schools of Lahore, Punjab.

\section{DATA ANALYSIS AND RESULTS}

The Statistical Package for the Social Sciences (SPSS), advanced version, was utilized for analysis of collected data in this research study. The analysis of data was carried out by descriptive statistical techniques which includes mean, simple linear regression, correlation, standard deviation and inferential statistics, reliability, one-way ANOVA and Cronbach alpha.

Table 1: Linear Regression: "Teacher Emotional Intelligence: SelfAwareness" as predictor of "Classroom Learning Environment: Students' involvement".

\begin{tabular}{lccc}
\hline Model 2 & B & SE & B \\
\hline (Constant) & 3.362 & .235 & \\
Teacher Emotional Intelligence: Self-Awareness & .128 & .058 & .152 \\
$\mathrm{R}$ & & & .575 \\
$R^{2}$ & & & .033 \\
$\Delta R^{2}$ & & & .021 \\
$F$ & & & $4.917^{*}$ \\
\hline
\end{tabular}

The effect of teachers' self-awareness on students' involvement in classroom is measured by applying liner regression. The results are presented in Table 1 which mention that teachers' self-awareness is strong predictor of students' involvement in classroom $(\mathrm{p}<.05)$. It also implies that $3.3 \%$ of variance in students' involvement in classroom was explained by the teachers' self-awareness. Hence, the Hypothesis 1 is rejected.

Table 2: Linear Regression: "Teacher Emotional Intelligence: SelfManagement" as predictor of "Classroom Learning Environment: Students' involvement"

\begin{tabular}{|c|c|c|c|}
\hline Model 2 & B & SE & B \\
\hline (Constant) & 3.349 & .241 & \\
\hline Teacher Emotional Intelligence: Self-Management & .134 & .060 & .152 \\
\hline $\mathrm{R}$ & & & .48 \\
\hline$R^{2}$ & & & .023 \\
\hline$\Delta R^{2}$ & & & .019 \\
\hline$F$ & & & $4.919 *$ \\
\hline
\end{tabular}


The effect of teachers' self-management on students' involvement in classroom is measured by applying liner regression. The results are presented in Table 2 which mention that teachers' self-management is strong predictor of students' involvement in classroom ( $\mathrm{p}<.05)$. It also implies that that $2.3 \%$ of variance in students' involvement in classroom was explained by the teachers' self-management. Hence, the Hypothesis 2 is rejected.

Table 3: Linear Regression: "Teacher Emotional Intelligence: SocialAwareness" as predictor of “Classroom Learning Environment: Students' involvement"

\begin{tabular}{lccc}
\hline Model 2 & B & SE & B \\
\hline (Constant) & 3.413 & .270 & \\
Teacher Emotional Intelligence: Social-Awareness & .116 & .067 & .120 \\
$\mathrm{R}$ & & & .119 \\
$R^{2}$ & & & .014 \\
$\Delta R^{2}$ & & & .012 \\
$F$ & & & $4.41^{*}$ \\
\hline
\end{tabular}

The effect of teachers' social-awareness on students' involvement in classroom is measured by applying liner regression. The results are presented in Table 3 which mention that teachers' social-awareness is a strong predictor of students' involvement in classroom ( $\mathrm{p}<.05)$. It also implies that that $1.4 \%$ of variance students' involvement in classroom was explained by the social awareness. Hence, the Hypothesis 3 is rejected.

Table 4: $\quad$ Linear Regression: "Teacher Emotional Intelligence: RelationshipSkills" as predictor of “Classroom Learning Environment: Students' involvement"

\begin{tabular}{lccc}
\hline Model 2 & B & SE & B \\
\hline (Constant) & 3.227 & .255 & \\
Teacher Emotional Intelligence: Relationship-Skills & .164 & .064 & .176 \\
$\mathrm{R}$ & & & .177 \\
$R^{2}$ & & & .031 \\
$\Delta R^{2}$ & & & .014 \\
$F$ & & & $6.63^{*}$ \\
\hline
\end{tabular}

The effect of teachers' relationship-skills on students' involvement in classroom is measured by applying liner regression. The results are presented in Table 4 which mention that teachers' relationship-skills are strong predictor of students' involvement in classroom $(\mathrm{p}<.05)$. It also implies that that $3.1 \%$ of variance of students' involvement in classroom was explained by the teachers' relationship-skills. Hence, 
the Hypothesis 4 is rejected.

Table 5: Linear Regression: "Teacher Emotional Intelligence: SelfAwareness” as predictor of "Classroom Learning Environment: Students' task orientation"

\begin{tabular}{lccc}
\hline Model 2 & B & SE & B \\
\hline (Constant) & 3.716 & .183 & \\
Teacher Emotional Intelligence: Self-Awareness & .157 & .045 & .187 \\
$\mathrm{R}$ & & & .65 \\
$R^{2}$ & & & .042 \\
$\Delta R^{2}$ & & & .018 \\
$F$ & & & $4.122^{*}$ \\
\hline
\end{tabular}

The effect of teachers' self-awareness on students' task orientation in classroom is measured by applying liner regression. The results are presented in Table 6 which mention that teachers' self-awareness is strong predictor of students' task orientation in classroom $(\mathrm{p}<.05)$. It also implies that $4.2 \%$ of variance in students' task orientation in classroom was explained by the teachers' self-awareness. Hence, the Hypothesis 6 is rejected.

Table 6: Linear Regression: "Teacher Emotional Intelligence: SelfManagement” as predictor of "Classroom Learning Environment: Students' task orientation"

\begin{tabular}{lccc}
\hline Model 2 & B & SE & B \\
\hline (Constant) & 3.735 & .188 & \\
Teacher Emotional Intelligence: Self-Management & .053 & .047 & .078 \\
$\mathrm{R}$ & & & .436 \\
$R^{2}$ & & & .019 \\
$\Delta R^{2}$ & & & .006 \\
$F$ & & & $4.34 *$ \\
\hline
\end{tabular}

The effect of teachers' self-management on students' task orientation in classroom is measured by applying liner regression. The results are presented in Table 7 which mention that teachers' self-management is strong predictor of students' task orientation in classroom $(\mathrm{p}<.05)$. It also implies that $1.9 \%$ of variance in students' task orientation in classroom was explained by the teachers' self-management. Hence, the Hypothesis 7 is rejected.

Table 7: Linear Regression: “Teacher Emotional Intelligence: SocialAwareness” as predictor of “Classroom Learning Environment: Students' task 


\begin{tabular}{lccc}
\hline orientation" & & & \\
\hline Model 2 & B & SE & B \\
\hline (Constant) & 4.145 & .210 & \\
Teacher Emotional Intelligence: Social-Awareness & .150 & .052 & .167 \\
$\mathrm{R}$ & & & .11 \\
$R^{2}$ & & & .012 \\
$\Delta R^{2}$ & & & .001 \\
$F$ & & & $5.3^{*}$ \\
\hline
\end{tabular}

The effect of teachers' social awareness on students' task orientation in classroom is measured by applying liner regression. The results are presented in Table 8 which mention that teachers' social awareness is a strong predictor of students' task orientation in classroom $(\mathrm{p}<.05)$. It also implies that $1.2 \%$ of variance students' task orientation in classroom was explained by the social awareness. Hence, the Hypothesis 8 is rejected.

Table 8: $\quad$ Linear Regression: “Teacher Emotional Intelligence: RelationshipSkills” as predictor of “Classroom Learning Environment: Students' task orientation"

\begin{tabular}{lccc}
\hline Model 2 & B & SE & B \\
\hline (Constant) & 3.754 & .200 & \\
Teacher Emotional Intelligence: Relationship-Skills & .248 & .050 & .266 \\
$\mathrm{R}$ & & & .195 \\
$R^{2}$ & & & .038 \\
$\Delta R^{2}$ & & & .022 \\
$F$ & & & $14.34 *$ \\
\hline
\end{tabular}

The effect of teachers' relationship-skills on students' task orientation in classroom is measured by applying liner regression. The results are presented in Table 9 which mention that teachers' relationship-skills are strong predictor of students' task orientation in classroom $(\mathrm{p}<.05)$. It also implies that $3.8 \%$ of variance of students' task orientation in classroom was explained by the teachers' relationship-skills. Hence, the Hypothesis 9 is rejected.

\section{DISCUSSION}

The research study was conducted to explore the effect of teacher's emotional intelligence on student's involvement \& task orientation in classroom learning environment at secondary school level. The teachers with high emotional intelligence are more capable to regulate their emotions, listen and understand students' perspective, create healthy and positive classroom learning environment. In such setup, 
students feel comfortable to voice their opinions and ultimately enhancing the success rate in students.

The finding of research study indicates that teachers' emotional intelligence helps them to create effective classroom learning environment and increase the involvement of students in various tasks efficiently which satisfy the research study's first objective. It is also supported by Jennings and Greenberg (2009) that effective teacher must utilize social and emotional competencies, to manage classroom efficiently. It is also very beneficial to strengthen the relationship between teacher, students, parents and peer to peer teacher relationships with other teachers. The results also depict strong relationship between teachers' emotional intelligence and students task orientation which was the second objective of research study. It is presented that student involvement and task orientation in classroom is positively affected by high emotional intelligence of teacher. It also helps students to improve their learning skills and enhance their academic achievement. Jafari and Ahmadzada (2014) have also suggested in their research that teachers' emotional intelligence and academic achievement has a strong relationship. Thus, teachers should focus to sharpen emotional intelligence skills and learn to regulate their emotions so as to achieve excellence in students' involvement and task orientation in classroom learning environment.

Research shows that emotional intelligence helps a teacher to develop better and more comfortable relationships with his students and to achieve a higher standard of living. Discipline on an emotional level refers to recognizing the feelings of others by organizing them with an awareness of one's true feelings. This is also supported by Madhar (2010) that emotional intelligence is very important factor for teacher in classroom management. It is also pointed out by Kelley (2018) that teachers who utilised emotional intelligent skills with students, it helped them to indulge students in classroom more effectively and tends to achieve better results.

\section{RECOMMENDATIONS}

The research study has presented that the teacher's emotional intelligence is very important aspect in classroom learning environment. Therefor it is recommended that special training on school management should be conducted regularly to enhance teachers' emotional intelligence skills. It is also recommended that the scope of future research work should be widened to include other variables of classroom learning environment, to examine the effect of teacher's emotional intelligence in broad spectrum. It will be also beneficial to increase the data sample size to future research studies and include secondary schools from other provinces than Punjab. 


\section{REFERENCES}

Akin-Little, K. A., Little, S. G., \& Laniti, M. (2007). Teachers' Use of Classroom Management Procedures in the United States and Greece: A Cross-Cultural Comparison. School Psychology International, 28(1), 53-62. https://doi.org/10.1177/0143034307075680

Bar-On, R., Maree, J. G., \& Elias, M. J. (Eds.). (2007). Educating people to be emotionally intelligent. Westport, Connecticut: Praeger.

Centers for Disease Control and Prevention (CDC). (2012). Youth violence: Facts at a glance 2012. Atlanta: U.S. Department of Health and Human Services. doi: http://www.cdc.gov/violenceprevention/pdf/yv-datasheet-a.pdf

Davis, S. (2005). Schools where everyone belongs: Practical strategies for reducing bullying. Champaign, IL: Research Press.

Desti, K., \& Shanthi, R. (2015). A Study on Emotional Intelligence At Work Place. European Journal of Business and Management, 7, 147-154. https://researchonline.jcu.edu.au/40340/1/40340\%20Kannaiah\%20and\%20Shanthi\% 202015.pdf

Durlak, J. A., Weissberg, R. P., Dymnicki, A. B., Taylor, R. D., \& Schellinger, K. B. (2011). The impact of enhancing students' social and emotional learning: A meta-analysis of school-based universal interventions. Child Development, 82(1), 405-432. doi:10.1111/j.1467-8624.2010.01564.x

Freedman, J. (2007). At the heart of leadership: How to get results with emotional intelligence. San Mateo, CA: Six Seconds Emotional Intelligence Press.

Galler, D. (2015). An exploration of how outstanding teachers use emotional intelligence to create positive classroom climates. https://rucore.libraries.rutgers.edu/rutgerslib/48177/PDF/1/play/

Goleman, D. (1995). Emotional Intelligence: Why it can matter more than IQ. Macmillan Audio.

Goleman, D. (2011). Leadership: The power of emotional intelligence. Northampton, MA: More than Sound LLC.

Howes, C. (2000). Social-emotional Classroom Climate in Child Care, Child-Teacher Relationships and Children's Second Grade Peer Relations. Social Development, 9(2), 191-204. https://doi.org/10.1111/1467-9507.00119

Howes, C.; Phillips, D.A.; \& Whitebrook, M. (1992). Threshold of quality: Implications for the social development of children in center-based child care. Child Development, $63,449-460$.

Jafari, M., \& Ahmadzade, F. (2014). Investigation of the association between the components of emotional intelligence and academic achievement in students. Razi Journal of Medical Sciences, 21(125), 85-93.

Jeloudar, S. Y., Yunus, A. S. M., Roslan, S., \& Nor, S. M. (2011). Teachers' Emotional Intelligence and Its Relation with Classroom Discipline Strategies Based on Teachers and Students' Perceptions. Journal of Psychology, 2(2), 95-102. https://doi.org/10.1080/09764224.2011.11885468

Jennings, P. A., \& Greenberg, M. T. (2009). The prosocial classroom: Teacher social and emotional competence in relation to student and classroom outcomes. Review of 
Educational Research, 79(1), 491-525.

Johansen, A., Little, S. G., \& Akin-Little, A. (2011). An Examination of New Zealand Teachers' Attributions and Perceptions of Behaviour, Classroom Management, and the Level of Formal Teacher Training Received in Behaviour Management. Kairaranga, 12(2), 3-12. https://iles.eric.ed.gov/fulltext/EJ954698.pdf

Madhar, M. A. (2010). Emotional Intelligence of Teachers and Effective Class Room Management. SSRN Electronic Journal, 1-14. https://doi.org/10.2139/ssrn.1666122

Noe, J. (2012). The Relationship between Principal's Emotional Intelligence Quotient, School Culture, and Student Achievement.

https://citeseerx.ist.psu.edu/viewdoc/download?doi=10.1.1.473.3221\&rep=rep1\&typ e=pdf\#: :text=There $\% 20$ is $\% 20$ no $\% 20$ significant $\% 20$ correlation, and $\% 20$ teacher $\% 20$ perceived $\% 20$ school $\% 20$ culture. $\&$ text $=$ There $\% 20$ is $\% 20$ no $\% 20$ significant $\% 20$ correl ation, \%2Dof\%2DCourse\%20reading\%20assessment.

Palmcrantz, M. (2018). Emotional Intelligence and Job Insecurity: Gender Differences between Employees. http://lnu.diva-portal.org/smash/get/diva2:

Pianta, R. C., La Paro, K. M., Payne, C., Cox, M. J., \& Bradley, R. (2002). The relation of kindergarten classroom environment to teacher, family, and school characteristics and child outcomes. Elementary School Journal, 102, 225 - 238.

Pugazhenthi, P., \& Srinivasan, P. (2018). Impact of teaching efficiency through emotional intelligence on the performance of B.ed teacher trainees. Global Journal for Research Analysis. Education, 7, 396-397.

Sadker, M.P., \& Sadker, D.M. (2005). Teachers, schools and society (7th ed.). 2005: McGrawHill.

Salfi, N. A. (2014). Perceptions of students about classroom management as a contributing factor towards learning at secondary school. Journal of Education and Human Development, 3(2), 713-728.

Serrat, O. (2017). Knowledge Solutions: Tools, Methods, and Approaches to Drive Organizational Performance (1st ed. 2017 ed.). Springer. https://doi.org/10.1007/978-981-10-0983-9_37

Swift, C. L. (2018). The Perceived Emotional Intelligence of Elementary Principals and Teachers' Job Satisfaction: Do They Relate? https://digitalcommons.

Wilson, H. K., Pianta, R. C., \& Stuhlman, M. (2007). Typical classroom experiences in first grade: The role of classroom climate and functional risk in the development of social competencies. The Elementary School Journal, 108(2), 81-96. 